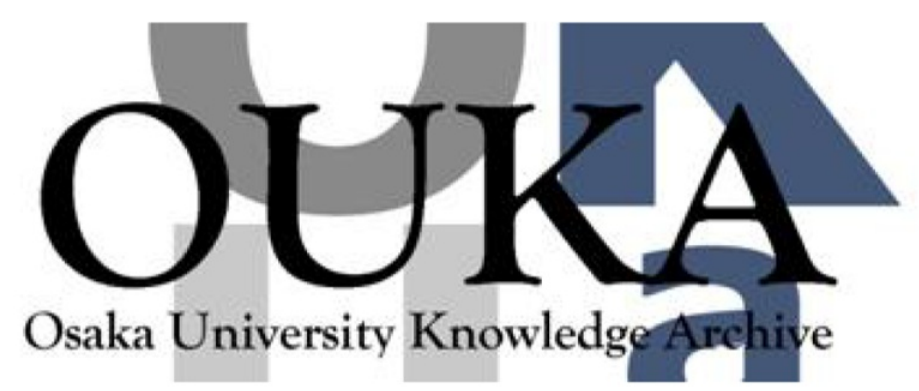

\begin{tabular}{|c|l|}
\hline Title & $\begin{array}{l}\text { ネットワーク境界越が可能なIEEE1888 over } \\
\text { Websocketの提案と実装 }\end{array}$ \\
\hline Author(s) & 樽谷, 優弥; 村田，修一郎; 松田，和浩 他 \\
\hline Citation & $\begin{array}{l}\text { システム制御情報学会研究発表講演会講演論文集. } \\
\text { 606-p.6 }\end{array}$ \\
\hline Issue Date & 2016 \\
\hline oaire:version VoR \\
\hline URL & https://hdl. handle. net/11094/71022 \\
\hline rights & \\
\hline Note & \\
\hline
\end{tabular}

Osaka University Knowledge Archive : OUKA

https://ir. Library. osaka-u. ac. jp/

Osaka University 


\title{
ネットワーク境界越が可能な IEEE1888 over Websocket の提案と実装 IEEE1888 over WebSocket for communicating across a network boundary
}

\author{
大阪大学 $\bigcirc$ 樽谷 優弥, 村田 修一郎, 松田 和浩, 松岡 茂登 \\ Osaka University $\bigcirc$ Yuya Tarutani, Shuichirou Murata, Kazuhiro Matsuda, and Morito \\ Matsuoka
}

\begin{abstract}
There is a network that restrains communication between inside equipment and outside equipment because of ensuring the security. In this case, each equipment cannot communicate with each other by a traditional IEEE1888 protocol. In this paper, we propose IEEE1888 over WebSocket for communicating across a network boundary. IEEE1888 over WebSocket provides an intercommunication between equipment across a network boundary without changing the system architecture of IEEE1888. We implemented and tested a proposed system.
\end{abstract}

\section{1 はじめに}

インターネット技術の普及に伴い、センサ機器やアク チュエータ機器との通信にインターネット技術が基盤と して用いられるようになっている。この動きは Internet of Things (IoT) と呼ばれる分野に発展し、多くの注 目を集めている。特に、ネットワークに接続されてい るセンサ機器やアクチュエータ機器から得られる情報 を用いて、電力使用状況の可視化や、接続機器の制御 等を行うことによりエネルギー消費の最適化を実現す るエネルギー管理システム (EMS:Energy Management System)[1-4] が注目を集めている。EMS には、家庭向 けの HEMS (HomeEMS) [1] や、ビル向けの BEMS (Building EMS) [2]、さらにはより広域を対象とした CEMS (Community EMS) [3] があり、多数のセンサ機 器やアクチュエータ機器等が接続され、情報のやり取り がなされる。しかしながら、多種多様な機器が存在する 状況では様々なプロトコル $[5,6]$ が用いられており、そ の実現は容易ではない。

この EMS 向けの通信プロトコルとして IEEE1888[7] が挙げられる。IEEE1888 はセンサ機器やアクチュエー 夕機器の情報収集や制御等を SOAP 通信 [8] で交換する プロトコルとして設計されており、その通信には Hyper Text Transper Protcol (HTTP) が用いられる。これに より、EMS の適用範囲をインターネット環境に拡大す ること、および様々な情報システムとの親和性を確保し ている。このように IEEE1888 は、インターネット基 盤が普及した現在では、広域、大規模な EMS に適した EMS 用プロトコルであると言える。しかしながら、セ キュリティ等の理由により通信が制限されたネットワー ク環境が存在する。例えば、ファイアウォールによって
内部からは通信が行うことができる一方で、外部からは ネットワーク内の機器に対して通信できない状況が考え られる。そのような通信が制限されたネットワーク環境 下の機器に対しても、ネットワーク外部の機器からセン サ機器の情被の収集やアクチュエータ機器の制御を行う ことが必要とされる。従来の IEEE1888 の仕組みでは、 このような環境下に存在する IEEE1888 コンポーネント に対して、そのネットワーク外部に存在する IEEE1888 コンポーネントから接続することはできない。

本研究では、このような通信が制限されたネットワー ク環境において、IEEE1888 コンポーネント同士による 相互接続や通信の実現する方法を提案する。提案方式 では、通信制限のあるネットワーク環境下の IEEE1888 サーバの URL を代理する URL をそのネットワークの外 部に用意し、かつ外部のネットワークにある IEEE1888 サーバの URL を代理する URL を通信制限のあるネッ トワーク内に朋意することにより、双方のネットワーク にある IEEE1888 コンポーネント同士を相互に到達可能 にする方法を採用する。また、代理 URL を提供するコ ンポーネント同士で WebSocket プロトコル [9] を用いた コネクションを確立することで、通信の双方向性をもた せ、双方のネットワークにある機器からの相互アクセス を実現する。提案方式は、IEEE1888 サーバの URL の 代理、および通信制限のあるネットワーク環境とその外 部ネットワークの間を結ぶ WebSocket コネクションを 構築するためのコンポーネントを追加するだけであり、 IEEE1888を使用した既存のネットワークに組み込みが 容易である。

本稿の章構成は以下のようになる。2 章では従来の IEEE1888 プロトコルの概要について述べる。3 章では 提案方式である IEEE1888 over WebSocket について述 


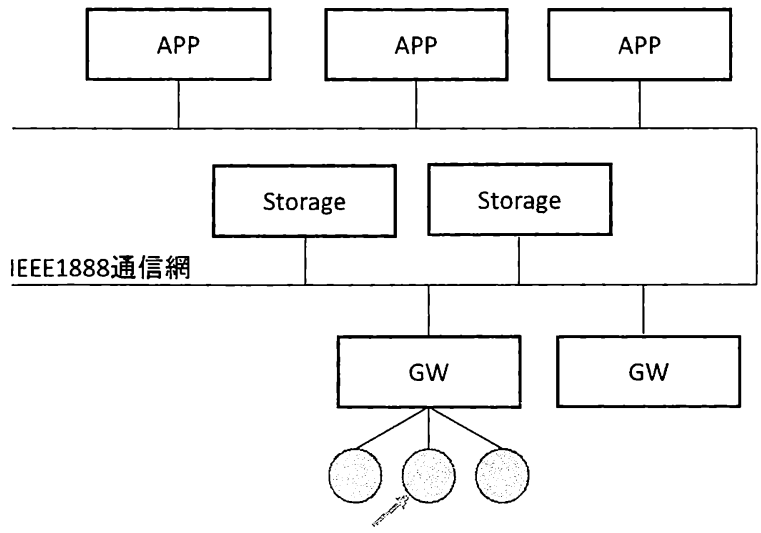

センサ機器、アクチュエータ機器

図 1: IEEE1888 のアーキテクチャ例

表 1: IEEE1888 の通信手段

\begin{tabular}{|c|c|}
\hline 通信手順 & 内容 \\
\hline FETCH & ストレージ等からデータを取得 \\
\hline WRITE & ストレージ等へデータを書き込む \\
\hline TRAP & $\begin{array}{c}\text { 情報の変更等に対し、指定した } \\
\text { コンポーネントに通知するように設定 }\end{array}$ \\
\hline
\end{tabular}

べる。4 章では、提案方式のプロトタイプを実装し、そ の接続試験について述べる。最後に本稿のまとめと今後 の課題について述べる。

\section{IEEE1888 プロトコル}

IEEE1888 は大規模エネルギーマネジメントシステム を構築、運用するためのプロトコルとして標準化された プロトコルである。図1に IEEE1888 のシステムアーキ テクチャを示す。IEEE1888 のシステムアーキテクチャ は、各種センサやアクチュエータ機器を扱うゲートウェイ （GW）、データを蓄積するためのストレージ（Storage）、 データの加工等の様々な役割を行うアプリケーション （APP）に分類される 3 種類の IEEE1888 コンポーネン トとその間を結ぶネットワークから構成される。これら の IEEE1888 コンポーネント間で IEEE1888 プロトコ ルを用いてデータ交換が行われる。

各 IEEE1888 コンポーネント間では通信手段として 表 1 FETCH、WRITE、TRAPの 3 つが定義されてい る。各IEEE1888 コンポーネントは識別子として URL を持っており、これらの通信手順は各URL を指定するこ とで行われる。IEEE1888 プロトコルでは、SOAP over HTTP に基づいて通信を行っている。IEEE1888 では

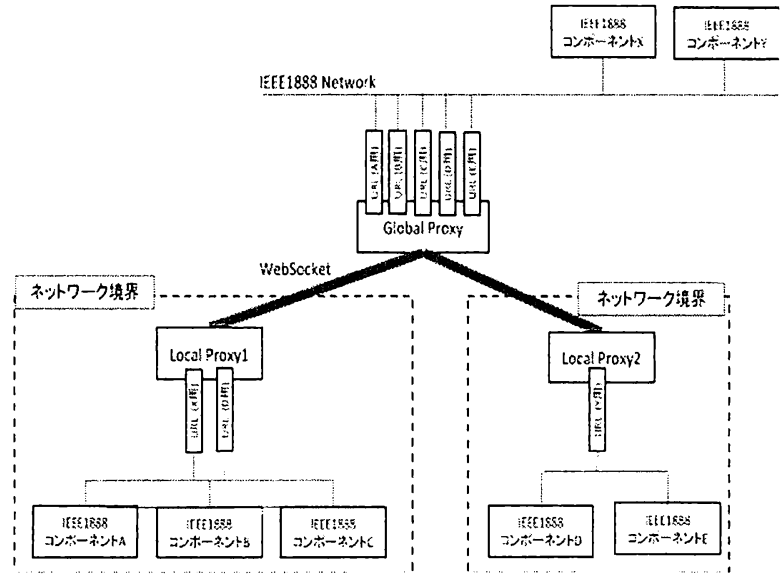

図 2: IEEE1888 over WebSocket のシステムアーキテ クチャ例

SOAP を採用することにより、Web 関連技術やデータ ベースなどの様々な情報システムとの親和性を高めてい る。また、HTTP による通信が可能な既設の LAN や広 域ネットワーク上でも容易に構築可能である。

しかしながらセキュリティ等の理由によって、ファイア ウォール等により通信が制限されたネットワーク環境内 に存在する IEEE1888 コンポーネントが存在する。この ような場合、ネットワーク内部から HTTP 通信が可能で あったとしても、その外部のネットワーク下のIEEE1888 コンポーネントからは、HTTP 通信ができない状況があ る。そのため、ネットワーク外部0 IEEE1888 コンポー ネントからは、コンポーネント間の相互通信を提供でき ない。そこで本稿では、このような状況でも IEEE1888 による通信を行うことができる方式を提案する。

\section{IEEE1888 over WebSocket}

\section{1 システムアーキテクチャ}

図 2 に提案する IEEE1888 over WebSocket のシス テムアーキテクチャの例を示す。図 2 に示すように、 IEEE1888 over WebSocket では、通信が制限されたネッ トワーク環境下 (以下ローカルネットワーク) のIEEE1888 コンポーネントとその外部ネットワーク側（以下グロー バルネットワーク）のコンポーネントとの相互通信のた めに、各ネットワーク間を WebSocket プロトコルを用 いたコネクション（以下 WebSocket コネクション）で 接続する。WebSocket コネクションによって、ローカル ネットワーク環境下の IEEE1888 コンポーネントに対し て、グローバルネットワーク側の IEEE1888 コンポーネ 


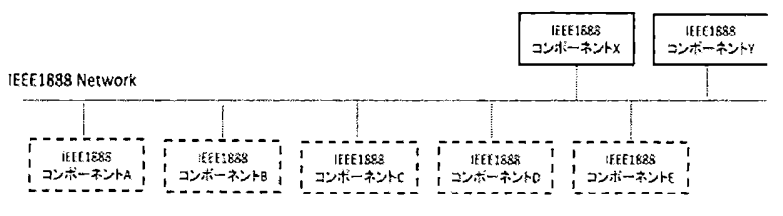

図 3: グローバルネットワーク側コンポーネントからみ た図 2 の IEEE1888 通信網

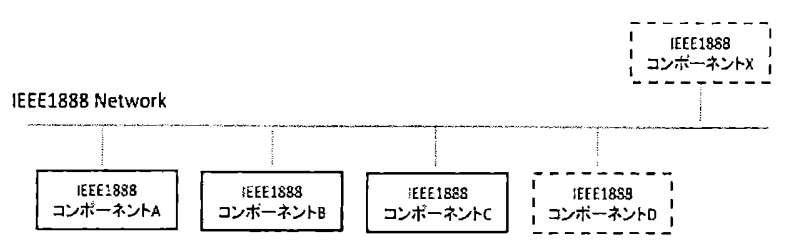

図 4: ローカルネットワーク側コンポーネントからみた 図 2 の IEEE1888 通信網

ントから通信を行うことができる。このネットワーク間 にWebSocket コネクションを模築する機器をそれぞれ Global Proxy および Local Proxy と乎ぶ。

\subsubsection{Global Proxy}

Global Proxy はグローバルネットワーク側に設置さ れ、WebSocket 用の URL を持っている。それとは別に、 ローカルネットワーク環境下の各 IEEE1888 コンポーネ ントに対応する複数の Proxy 用の URL を持っている。 各 URL 宛に送られた通信は WebSocket コネクション を通じて Local Proxy に転送され、表 2 に示すような 変換表に基づいて、対応する IEEE1888 コンポーネン トに送信される。このように Global Proxy がローカル ネットワーク環境下の IEEE1888 コンポーネントの代理 をすることによって、グローバルネットワーク側にある IEEE1888 コンポーネントからローカルネットワーク環 境下の各コンポーネントが図 3 のように見える。図中 の実線と点線で表されたコンポーネントは、それぞれグ ローバルネットワーク側の IEEE1888 コンポーネントが Global Proxy を用いずに接続が可能なコンポーネント、 および Global Proxy を介して接続するコンポーネント である。

\subsubsection{Local Proxy}

Local Proxy はローカルネットワーク環境下に設置され る。Local Proxyは、Global Proxy との間に WebSocket コネクションを構築し、Global Proxy から転送された 通信を、表 3 に示すような変換表に基づいて、送られた

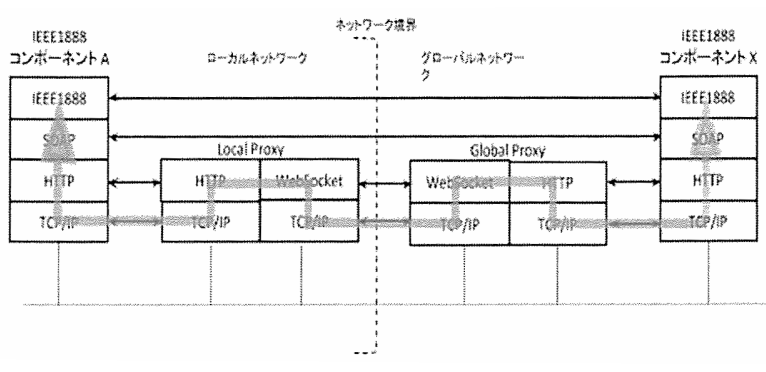

図 5: IEEE1888 over WebSocket のレイヤ・アーキテク チャ

Proxy 用のURL に対応するローカルネットワーク環境下 の IEEE1888 コンポーネントに送信する。Local Proxy も Global Proxy と同様に Proxy 用 URL を提供する機 能を持つ。例えば、図 2 に示すように、Local Proxy1 が提供している「URL(X 用)」「URL(D 用)」、および Local Proxy2 が提供している「URL (Y 用)」に対して 通信を行うと、各 Proxy を経由して、それぞれ対応す るIEEE1888 コンポーネントとの通信ができる。その ため、Local Proxy1 が設置されているネットワークの 各コンポーネントからは他のコンポーネントがそれぞれ 図49ように見える。図中の実線と点線で表されたコン ポーネントは、それぞれ LocalProxy1 が所属するネッ トワーク内部のIEEE1888 コンポーネントが直接アクセ スできるコンポーネント、抽びLocal Proxy1 を介し てアクセスできるコンポーネントである。

\section{2 レイヤアーキテクチャ}

IEEE1888 over WebSocket ではコンポーネント-プロ キシ間と Global Proxy-Local Proxy 間 (Proxy 間) で 異なる通信方法が用いられる。コンポーネントープロキ シ間では通常の IEEE1888 におけるコンポーネント間 の通信を行う。Proxy 間では、TCP/IP のセッション を構築し、HTTP リクエストによってコネクションの UPGRADE 要求を行い、Proxy間の TCP/IP のセッショ ン上に WebSocket コネクションを構築する。WebSocket コネクションの構築後、各コンポーネントから受信した HTTP メッセージを Proxy 間の接続を通して転送する ことにより通信を実現する。

図 5 にIEEE1888 over WebSocket のレイヤ・アーキテ クチャの例を示す。図 5 に示すように IEEE1888、SOAP のレイヤでは、通信の方向にかかわらず、各コンポーネ ントから送られてきたメッセージはプロキシを通じて宛 先のコンポーネントに送られる。通常、各プロキシでは、 これらのレイヤのメッセージは処理を行うことなく、透 
表 2: Global Proxy のエンドポイント変換表の例

\begin{tabular}{|c|c|}
\hline Global Proxy が提供するエンドポイント URL & 実際の接続先 IEEE1888 コンポーネントのエンドポイント URL \\
\hline http://globalproxy.example.com/A & http://local-ieee1888.exmaple.com/A \\
\hline http://globalproxy.example.com/B-8888 & http://local-ieee1888.example.com:8888/B \\
\hline http://globalproxy.example.com/192-C & $\mathrm{http}: / / 192.168 .0 .10 / \mathrm{C}$ \\
\hline
\end{tabular}

表 3: Local Proxy のエンドポイント変換表の例

\begin{tabular}{|c|c|}
\hline Local Proxy が提供するエンドポイント URL & 実際の接続先 IEEE1888 コンポーネントのエンドポイント URL \\
\hline http://localproxy.example.com/A & http://global-ieee1888.example.com/A \\
\hline http://localproxy.example.com/B-8888 & http://global-ieee1888.example.com:8888/B \\
\hline http://localproxy.example.com/1-C & http://global-ieee1888-1.example.com/C \\
\hline
\end{tabular}

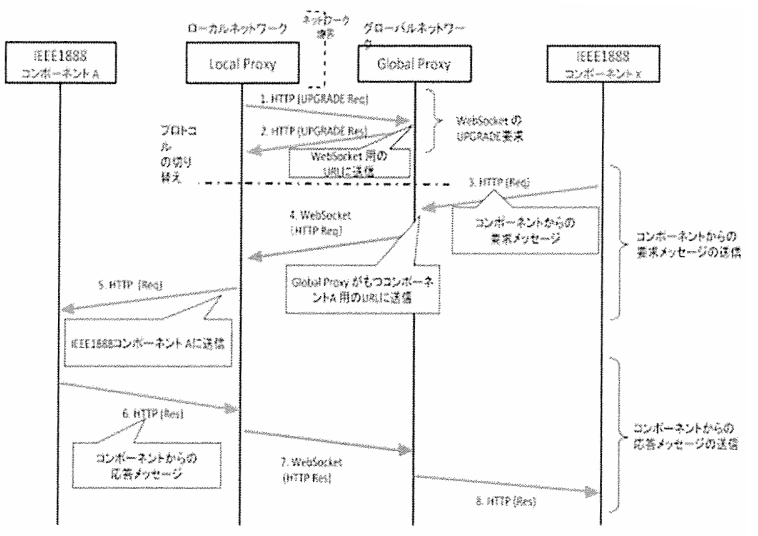

図 6: IEEE1888 over WebSocket の通信手順の例

過的に宛先のコンポーネントへ送信される。プロキシは HTTPヘッダーを参照し、どのプロキシやコンポーネン トにメッセージを転送するかを決定する。図5に抽いて、 コンポーネント X からコンポーネント A への通信の場 合、宛先の URL は Global Proxy のもつ URL であり、 Global Proxy はそれを参照して、Global Proxy がどの Local Proxy に転送するか、またLocal Proxy がどのコ ンポーネントに送信するかを決定する。Local Proxy も Global Proxy と同様の転送用 URL を提供し、宛先を 実際のコンポーネントの URL に変換したのち、Global Proxy に転送する。WebSocket レイヤでは、コンポーネ ントから受け取った HTTP メッセージを WebSocket の Data フレームに格納して対象のプロキシに転送する。

\section{3 通信手順}

図 6 に IEEE1888 over WebSokcet を用いた通信手順 の例として、グローバルネットワーク側のコンポーネン トからローカルネットワーク側のコンポーネントへの通 信手順を示す。各手順の具体的な動作内容は以下の通り である。

1. Local Proxy がGlobal Proxyに対して、WebSocket コネクションの接続要求（UPGRADE Req）を送 信する。

2. Global Proxy は Local Proxy に UPGRADE Res を返す。結果として、Local Proxy、Global Proxy 間に WebSocket コネクションが確立される。

3. IEEE1888 コンポーネント X は Global Proxy が 持つコンポーネント A 用の URL 宛に要求メッ セージを送信する。

4. Global Proxy は受け取った要求メッセージを WebSocket のコネクションを用いて Local Proxy に転 送する。

5. Local Proxy は IEEE1888コンポーネント A に対 して、要求メッセージを送信する。

6. IEEE1888 コンポーネント A は受信した要求メッ セージに対しての忘答メッセージを、Local Proxy に返す。

7. Local Proxy は WebSocket コネクションを通じて 応答メッセージを Global Proxy に転送する。 


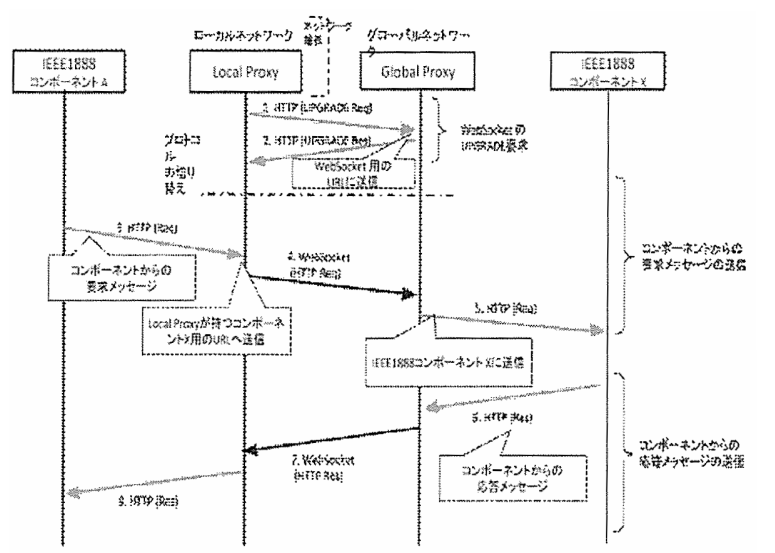

図 7: IEEE1888 over WebSocket の通信手順の例

8. Global Proxy は受け取った応答メッセージをIEEE1888 コンポーネントXに対して送信する。

また、図 7 にローカルネットワーク側のコンポーネン トからグローバルネットワーク側のコンポーネントへの 通信手順を示す。各手順の具体的な動作内容は以下の通 りである。

1. Local Proxy がGlobal Proxyに対して、WebSocket コネクションの接続要求 (UPGRADE Req) を送 信する。

2. Global Proxy は Local Proxy に UPGRADE Res を返す。結果として、Local Proxy、Global Proxy 間に WebSocket コネクションを確立する。

3. IEEE1888 コンポーネント A は Local Proxy がも つコンポーネント X 用の URL 宛に要求メッセー ジを送信する。

4. Local Proxy は WebSocket を通して Global Proxy に要求メッセージを転送する。

5. Global Proxy は転送された要求 コンポーネント X に送信する。

6. 要求メッセージを受け取った IEEE1888 コンポー ネント X は Global Proxy に対して応答メッセー ジを返す。

7. Global Proxy は Local Proxy に対して応答メッ セージを転送する。

8. Local Proxy は転送された応答メッセージを IEEE1888 コンポーネント A に対して返送する。

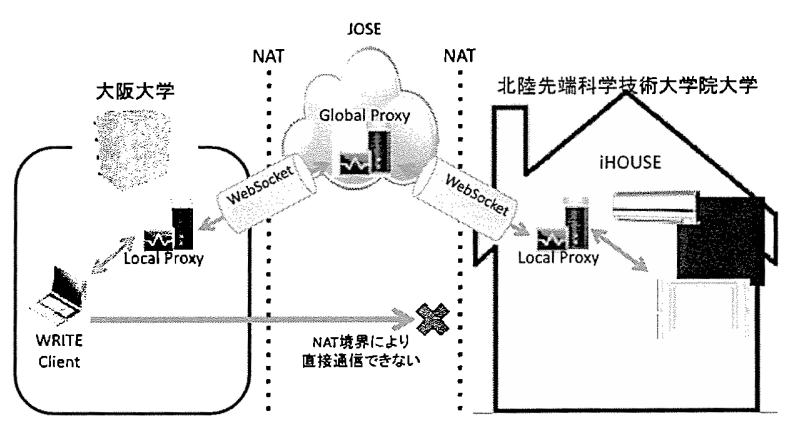

図 8: 動作検証概略

\section{4 動作検証}

本稿で提案した IEEE1888 over WebSocket のプロト タイプを实装し、その動作検証をおこなった。動作検証 のために、3 拠点間における接続テストを行った。図 8 に行った接続テストの概略を示す。本検証では、大規模 オープンテストベッドである、JOSE（Japan-wide Orchestrated Smart/Sensor Environment)[10] Proxy を配置し、大阪大学および北陸先端科学技術大 学院大学に Local Proxyを設憩した。そして、大阪大 学内のネットワークの IEEE1888 コンポーネントから、 各Proxy を通じて、北陸先端科学技術大学院大学内に あるテストベッドである iHouse[11] 内の機器に対して、 WRITE 要求を送り、機器を㸡御することで接続試験を 行った。本検証における WRITE クライアントおよび GW サーバは Python で实装し、各 Proxy は Java を用 いて実装した。WebSocketコネクションはそれぞれの Local Proxy 起動時に Global Proxy に対して棈築する。 また、大阪大学側の Local Proxy の Proxy 用 URL が北 陸先端科学技術大学院大学内の GW サーバの URL に対 応するように設定を行った。

結果としては、大阪大学内の WIRTE クライアントか ら Local Proxy の代替 URL を指定して WRITE 命令 を送信することで、北陸先端科学技術大学院大学に設真 \&た GWサーバに接続している機器を制御できること を確認した。すなわち、本稿で提案した IEEE1888 over WebSocket が正しく動作し、通常の方法では通信不可 能な IEEE1888 コンポーネントに対しても通信が可能と なることが確認できた。

\section{5 おわりに}

本稿では、セキュリティ等の理由によって通信が制限 され、通常の方法では相互通信ができない IEEE1888 コンポーネント間において、相互通信の実現のために、 
IEEE1888 over WebSocket を提案した。本稿で提案し た IEEE1888 over WebSocket は既存の IEEE1888 ネッ トワークに WebSokcet コネクションを構築するための 2 種類の Proxy を追加することで、通常の方法では相 互通信ができない IEEE1888 コンポーネント間におい ても相互通信を実現することができる。本稿では、提案 した IEEE1888 over WebSocket のプロトタイプを実装 し、その動作検証を行った。その結果、通常の方法では 通信不可能な IEEE1888 コンポーネントに対しても通 信が可能となることが確認した。本稿で提案している IEEE1888 over WebSokcet では、各 Proxy を経由する ことによる遅延への影響や構築する WebSocket コネク ションの数による影響を考慮していない。そのため、大 規模エネルギーマネジメントシステムへの適用のために はこれらの検討を行うことが課題として挙げられる。ま た、本稿で提案している IEFE1888 over WebSocket は、 IEEE の標準化を視野にいれて活動学行こている。

\section{謝辞}

本研究の一部は、情報通信研究機構（NICT）の委託 研究「新世代ネットワークの実現に向けた欧州との連携 による共同研究開発および実証」の支援による。ここに 記して謝意を表す。

\section{参考文献}

[1] H. T. Nguyen, D. Nguyen, and L. B. Le, "Home energy management with generic thermal dynamics and user temperature preference," in Proceedings of IEEE SmartGridComm, pp. 552-557, Oct. 2013.

[2] K. Park, Y. Kim, S. Kim, K. Kim, W. Lee, and H. Park, "Building energy management system based on smart grid," in Proceedings of IEEE INTELEC, pp. 1-4, Oct. 2011.

[3] 鈴木浪平, 田熊良行, 井野本正樹, 谷本昌彦, “地域 エネルギーマネジメント技術 (CEMS)," 三菱電機 技法.

[4] 中村雅之、竹内章、榎本裕幸: “データセンタエネル ギー管理システム (DEMS) の ICT 一空調連係制御 技術による省電力への取り組み:" NTT 技術ジャー ナル, pp. 15--19, Nov. 2012.

[5] "ECHONET Web Page." Available at http:// www. echonet.gr.jp/.
6] J. Case, M. Fedor, M. Schoffstall, and C. Davin, "RFC 1157: Simple Network Management Protocol (SNMP)," 1989. Available at http://www. hjp.at/doc/rfc/rfc1157.html.

17] "IEEE1888 (FIAP) - 東大グリーン ICT プロジェ クト." Available at http://www.gutp.jp/fiap/.

[8] D. Box, D. Ehnebuske, G. Kakivaya, A. Layman, N. Mendelsohn, H. F. Nielsen, S. Thatte, and D. Winer, "Simple object access protocol (soap) $1.1, " 2000$.

[9] "WebSocket Web Page." Available at http:// www.websocket.org/.

[10] “大規模オープンテストベッド jos.” http://www . nict.go.jp/nrh/nwgn/jose.html.

[11] W. W. Shein, Y. Tan, and A. O. Lim, "PID controller for temperature control with multiple actuators in cyber-physical home system," International Transaction on Systems Science and Applications, vol. 8, pp. 149-166, Dec. 2012. 